\title{
Microfluidic chip enables single-cell measurement for multidrug resistance in triple-negative breast cancer cells
}

\author{
Karan Parekh ${ }^{1,2}$, Hamideh Sharifi Noghabi ${ }^{1,2}$, Jose Alejandro Lopez ${ }^{3}$, Paul Chi Hang Li ${ }^{1,2}$ \\ 'Department of Molecular Biology \& Biochemistry, Simon Fraser University, Burnaby V5A 1S6, Canada. \\ 2Department of Chemistry, Simon Fraser University, Burnaby V5A 1S6, Canada. \\ ${ }^{3}$ School of Environment \& Science, Griffith University, Nathan, Queensland 4111, Australia.
}

Correspondence to: Prof. Paul Chi Hang Li, Department of Chemistry, Simon Fraser University, Burnaby, Canada V5A1S6, Canada.E-mail: paulli@sfu.ca

How to cite this article: Parekh K, Noghabi HS, Lopez JA, Li PCH. Microfluidic chip enables single-cell measurement for multidrug resistance in triple-negative breast cancer cells. Cancer Drug Resist2020;3:613-22.

http://dx.doi.org/10.20517/cdr.2019.77

Received: 20 Sep 2019 First Decision: 20 Dec 2019 Revised: 3 Jan 2020 Accepted: 16 Jan 2020 Available online: 11 Mar 2020

Science Editor: Dario Marchetti Copy Editor: Jing-Wen Zhang Production Editor: Tian Zhang

\begin{abstract}
Aims: Triple-negative breast cancer patients are commonly treated with combination chemotherapy. Nonetheless, outcomes remain substandard with relapses being of a frequent occurrence. Among the several mechanisms that result in treatment failure, multidrug resistance, which is mediated by ATP-binding cassette proteins, is the most common. Regardless of the substantial studies conducted on the heterogeneity of cancer types, only a few assays can distinguish the variability in multidrug resistance activity between individual cells. We aim to develop a single-cell assay to study this.
\end{abstract}

Methods: This experiment utilized a microfluidic chip to measure the drug accumulation in single breast cancer cells in order to understand the inhibition of drug efflux properties.

Results: Selection of single cells, loading of drugs, and fluorescence measurement for intracellular drug accumulation were all conducted on a microfluidic chip. As a result, measurements of the accumulation of chemotherapeutic drugs (e.g., daunorubicin and paclitaxel) in single cells in the presence and absence of cyclosporine A were conducted. Parameters such as initial drug accumulation, signal saturation time, and fold-increase of drug with and without the presence cyclosporine A were also tested.

Conclusion: The results display that drug accumulation in a single-cell greatly enhanced over its same-cell control because of inhibition by cyclosporine A. Furthermore, this experiment may provide a platform for future liquid biopsy studies to characterize the multidrug resistance activity at a single-cell level.

cc) (i) ( $\odot$ The Author(s) 2020. Open Access This article is licensed under a Creative Commons Attribution 4.0 International License (https://creativecommons.org/licenses/by/4.0/), which permits unrestricted use, sharing, adaptation, distribution and reproduction in any medium or format, for any purpose, even commercially, as long as you give appropriate credit to the original author(s) and the source, provide a link to the Creative Commons license, and indicate if changes were made.

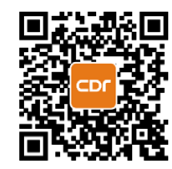


Keywords: MDA-MB-231 cell, triple-negative breast cancer, microfluidic chip, lab-on-chip, multidrug resistance, singlecell analysis, fluorescence measurement

\section{INTRODUCTION}

Despite the recent progression in cancer treatments, breast cancer is still the most common female malignancy worldwide ${ }^{[1]}$. In breast cancer, malignant epithelial cells can be unresponsive or hyperactive to the hormones, estrogen, and progesterone ${ }^{[2]}$, resulting in uncontrolled cellular growth and proliferation. Triple-negative breast cancer (TNBC), which lacks expression of the estrogen, progesterone, and HER2 receptor, is often a basal-like breast cancer capable of growing high-grade aggressive tumors that can spread quickly. As a result, neither hormonal therapy nor targeted therapy is offered for triple-negative or basallike breast cancers ${ }^{[2]}$. Therefore, many cancer patients are prescribed with conventional chemotherapies and targeted radiation therapies, which generally involve a combination of drugs and regimens. While novel immunotherapies have shown great promise in several cancers, in TNBC, only very tentative initial trials have been completed. It appears that the best option for those approaches to be effective will be as part of a mix of therapeutic approaches that also includes chemotherapy and targeted therapies.

A major drawback to the success of combination chemotherapy in TNBC patients is the non-responsive nature of cancer cells to a range of chemotherapeutic agents, an occurrence known as multidrug resistance $^{[2,3]}$. A major cause of multidrug resistance (MDR) involves the hyperactive efflux of hydrophobic cytotoxic drugs mediated by ATP-binding cassette $(A B C)$ proteins in mammary epithelial cells. Three commonly observed $\mathrm{ABC}$ proteins, which are relevant in $\mathrm{MDR}$ in breast cancer, include $\mathrm{ABC}$ transporter subfamily B member 1 or P-glycoprotein, $\mathrm{ABCC}$, and breast cancer resistance protein (or ABC subfamily G member 2$)^{[4-8]}$. Such protein transporters function as efflux pumps for hydrophobic compounds, which intensify the transport of chemotherapeutic drugs, resulting in an ultimate reduction of the intracellular drug concentration and ineffective cancer therapy. Inhibition of these $\mathrm{ABC}$ proteins can possibly inverse the cells' MDR mechanism and cultivate a prospect to increase the cellular drug accumulation, with the intention of improving the success of cancer therapy ${ }^{[9]}$. The use of $\mathrm{ABC}$ transporter inhibitors such as cyclosporine $\mathrm{A}^{[10]}$ and fumitremorgin $\mathrm{C}^{[11]}$ have been previously reported.

Traditionally, MDR function was studied by measuring drug accumulation using a variety of methods including, but not limited to, radiolabeling-based microtiter plate assays and flow-cytometry ${ }^{[12]}$. However, such methods have been publicized to be mechanically demanding and time-consuming with additional drawbacks. First, these methods are "bulk assays" and thus such experiments require cell samples in large numbers to generate statistically significant results; however, obtaining cells in great number is not always possible. Moreover, biological heterogeneity is notable only at an individual cell level, and such large cell populations are heterogeneous and therefore bulk assays cannot reveal the MDR variations at the cellular level ${ }^{[13]}$.

To address these issues, we adopted the microfluidic chip technology, which has greatly advanced in past few decades, enabling researchers to study many disease mechanisms ${ }^{[14-18]}$. The microfluidic chip has been simulated, designed, and tested for studying polymeric particles and biological cells ${ }^{[19-23]}$. Moreover, in comparison with conventional methods, the microfluidic method has many advantages when using liquid biopsy samples ${ }^{[24]}$. Firstly, because of the narrow size of the microchannel, it is easier to isolate a single cell in the microchannel than in a bulk solution. Second, because of no evaporation of cell medium, microfluidic experiments on a single-cell level can be performed for an extended period of time without the concern of cell death. Lastly, no change in fluorescence will occur owing to the variation in the liquid 


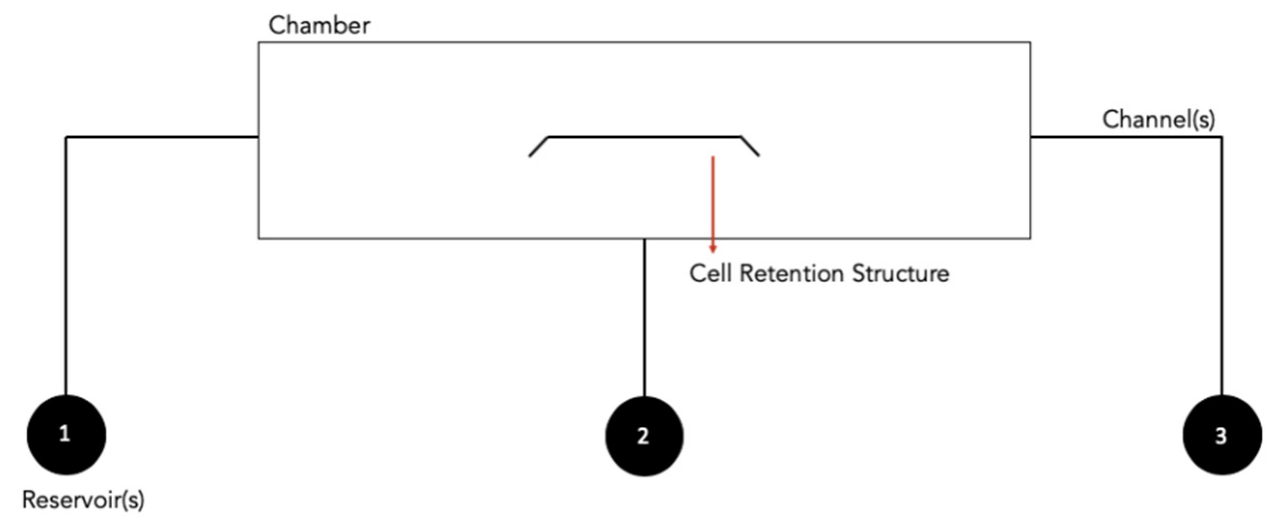

Figure 1. Design layout of the microfluidic chip. A structure of the chip, with the left (1) and right (3) reservoirs serving as the cell inlet and waste reservoirs, respectively, whereas the middle reservoir (2) is used for reagent delivery

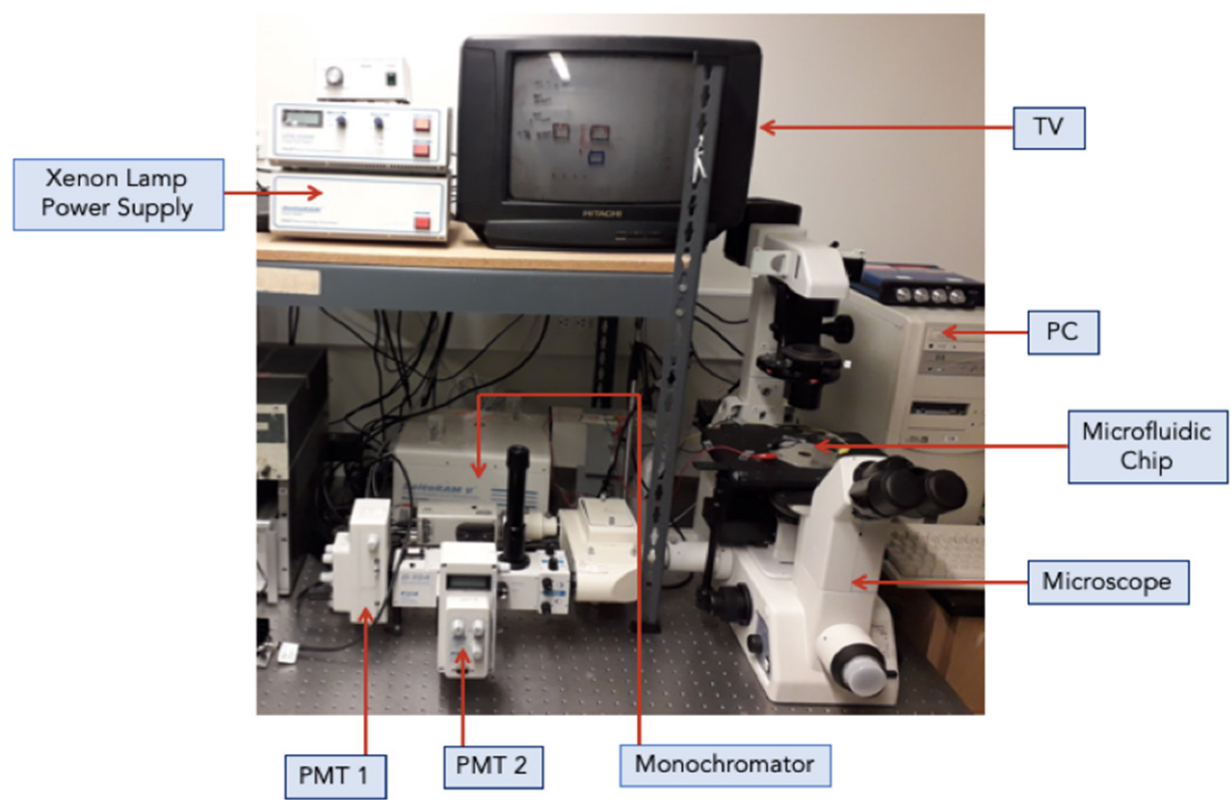

Figure 2. Nikon-PTI optical measurement-imaging system setup. PMT: photomultiplier tube

depth at the observation region. As a result, single-cell assays can retain details of individual cells that are otherwise masked out in bulk cell assays ${ }^{[19,20,23]}$.

In this paper, the MDR assay of drug accumulation was performed in the absence of, and then presence of, an MDR inhibitor to permit the same cancer cell to serve as its own internal control. In addition, we demonstrate that the single-cell method provides time-dependent cellular drug transport data and permits morphological interrogation, which allows us to categorize different single cells.

\section{METHODS}

\section{Microfluidic chips}

The microfluidic chip (30 $\mathrm{mm} \times 30 \mathrm{~mm}$ ), as shown in Figure 1, comprises three major reservoirs, three channels, and a single chamber which contains a cellular retention structure. The microfluidic chip was fabricated by the standard micromachining processes at CMC Microsystems (Kingston, ON, Canada), which included standard glass cleaning, photolithography, photoresist development, reservoir forming on 
a cover plate, and chip bonding ${ }^{[25,26]}$. Reservoirs 1 and 3 (Left and Right) function as cell inlet and waste reservoirs, respectively, whereas Reservoir 2 channels drug delivery. Each channel is $40 \mu \mathrm{m}$ deep, whereas the reservoirs, which are $2.5 \mathrm{~mm}$ in diameter, are $0.6 \mu \mathrm{m}$ deep.

\section{Fluorescence detection system}

In Figure 2, an optical imaging system, consisting of an inverted microscope (TE300, Nikon, Mississauga, ON, Canada), was connected to a video camera (TK-CC3180; JVC, Yokosuka, Japan) for simultaneous fluorescence measurements and bright-field imaging, as previously described ${ }^{[27-29]}$. A TV (Hitachi) and VCR system (JVC) was used for easy microscopic observation. A video capture card (ATI-TV Wonder bt878, Markham, ON, Canada) was installed in the computer for image capture.

Optical excitation $(470 \mathrm{~nm})$ was provided by a Xenon arc lamp (Photon Technologies International, London, Ontario, Canada) coupled to a monochromator. A dichroic filter (620 nm) was used for only red light to enter the video camera for cell imaging, whereas the green fluorescent emission (535 nm) was transmitted to the microphotometer system (PTI, Charlotte, NC) through a detection aperture. Data were processed by the Felix Software (PTI).

\section{Cell samples and reagents}

For the MDR assays, daunorubicin (DNR, Sigma-Aldrich, St. Louis, MO) and cyclosporine A (CsA, SigmaAldrich) were dissolved in dimethyl sulfoxide (DMSO, Sigma-Aldrich) to make stock solutions of $350 \mu \mathrm{M}$ and $1 \mathrm{mM}$, respectively. Working solutions of $35-\mu \mathrm{M}$ DNR and $5-\mu \mathrm{M}$ and $10-\mu \mathrm{M}$ CsA were prepared by diluting stock solutions in Hanks' Balanced Salt Solution (HBSS, Invitrogen Corp., Grand Island, NY). Working solutions of $1-\mu \mathrm{M}$ Oregon Green-labeled paclitaxel (OG-PTX) and $10-\mu \mathrm{M}$ CsA were prepared by diluting stock solutions in a similar fashion. Post-assay cell viability was tested using $0.4 \%$ trypan blue solution (ThermoFisher Scientific, Waltham, MA).

The MDA-MB-231 breast cancer cell lines were obtained from cryopreserved storage. The cells were maintained in Hyclone Dulbecco's Modified Eagle Medium (DMEM)/High Glucose (GE Life Science, Marlborough, MA) with 10\% fetal bovine serum (FBS, Life Technologies, Grand Island, NY) and 1\% penicillin (Stemcell Technologies, Vancouver, BC) at $5 \% \mathrm{CO}_{2}$ and $37{ }^{\circ} \mathrm{C}$. The doubling time for the cell lines was $\sim 38 \mathrm{~h}$; hence, growth medium was changed three times a week and cells were passaged every $72 \mathrm{~h}$.

\section{Selection and retention of single cells}

Mammary epithelial cells are adherent and therefore will readily adhere to the surface of the microchip, as reported in previous microchip studies with adherent cells ${ }^{[29,30]}$. Prior to starting the experiment, the reservoirs and channels of the microfluidic chip were washed using a soap solution, rinsed with double distilled water, and sterilized with $75 \%$ ethanol. Once the chip was washed and sterilized, a $5-\mu \mathrm{L}$ aliquot of cell medium solution was added to Reservoirs 2 and 3 to craft an environment suitable for cell survival. Thereafter, a $5-\mu \mathrm{L}$ aliquot of cell suspension was introduced into the cell inlet (Reservoir 1; see Figure 1 for notations), and a small amount of cell medium was removed from Reservoir 3, resulting in the cell moving from left to right, as shown in the schematic diagram for the transport and retention of the breast cancer single-cell in Figure 3. When the cell moved close to the cell retention structure, some cell medium was added to the right (Reservoir 3). In this way, the liquid pressure difference was established, and a desired cancer cell was moved and stabilized in position near or around the cell retention structure. Single cells were selected based on size and morphological criteria for drug accumulation measurements.

Once the cell remained stationary in position, a 10-min incubation period was provided for the cell to adhere to the surface of the microchip. After the cell had adhered to the chamber surface, liquid from all three reservoirs was removed and fresh medium solution was added to all three reservoirs. The cell was then settled for an additional 5 min before fluorescence measurements commenced. 
A

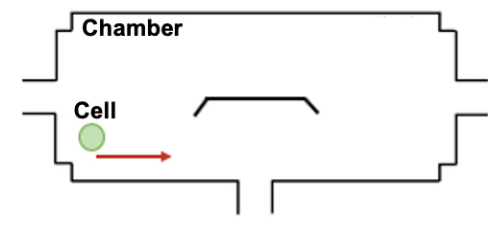

B

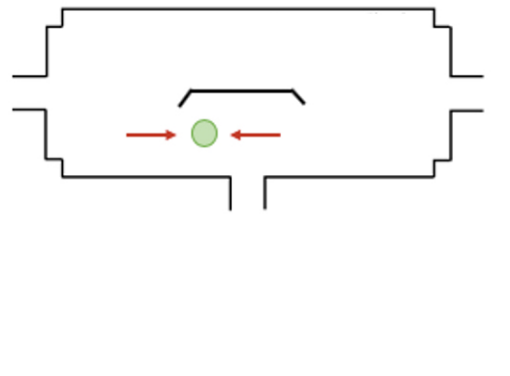

C

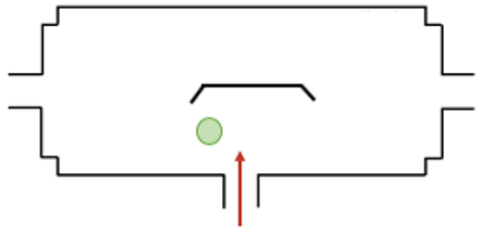

Figure 3. Schematic diagrams displaying how a single breast cancer cell was sorted and retained near the cell retention structure. A: Cell suspension was inserted through Reservoir 1; B: The liquid level of Reservoirs 1 and 3 was adjusted to make the cell stop near the cell retention structure; C: Upon cell retention, chemical reagents were administrated through Reservoir 2

\section{Drug accumulation measurement on the single cancer cells}

After a single MDA-MB-231 breast cancer cell had adhered to the chamber of the microfluidic chip and been selected for, based on size and morphological criteria, the observation aperture for fluorescence measurement was adjusted, and two detection boxes, which equated to a size approximately $1 \mathrm{~cm}$ larger than the cell, were marked on the TV monitor to provide a visual observation during the experiment. Afterward, cell media in all reservoirs were removed, and then the drug inlet reservoir was filled with a $5-\mu \mathrm{L}$ aliquot of $35-\mu \mathrm{M}$ DNR. Fluorescence measurement $\left(\lambda_{\mathrm{ex}}=470 \mathrm{~nm} ; \lambda_{\mathrm{em}}=585 \mathrm{~nm}\right)^{[24,30,31]}$ began, which was to monitor the increase in fluorescence due to the accumulation of DNR in the cell in the absence of CsA, an MDR inhibitor. Thereafter, DNR accumulation was measured in the same single cell in the presence of a $5-\mu \mathrm{L}$ aliquot of $5-\mu \mathrm{M}$ CsA to observe an enhanced drug accumulation due to MDR inhibition. Similar experiments were run using $1-\mu \mathrm{M}$ OG-PTX in the presence and absence of $10-\mu \mathrm{M}$ CsA. The cell signal and the background were measured at two different detection sites, within the cell and outside the cell. To achieve this, the position of the chip was controlled by manually adjusting the chip back and forth between two detection sites. In Figure 4B, the detection site was outside the cell, in which the extracellular fluorescence intensity was detected. Figure $4 \mathrm{C}$, in which the detection site was on the cell, provides the total fluorescence intensity. Translation of the chip was conducted in such a way that the aperture measured cellular fluorescence for $10 \mathrm{~s}$ and extracellular fluorescence for $60 \mathrm{~s}$. Subtraction of the cell signal from the background gave a corrected signal representing the drug accumulation fluorescence in the cell. After all experiments, cells were treated with trypan blue, a small negatively charged dye, which only stains cells with a compromised cell membrane in order to test cell viability ${ }^{[32]}$.

\section{RESULTS}

Initially, a single TNBC cell was introduced and retained in the microfluidic chip. Then, fluorescence measurement of the retained cell was conducted using the fluorescence detection system for $\sim 1600 \mathrm{~s}$. The cancer cell was first treated with $35-\mu \mathrm{M}$ DNR for $\sim 700 \mathrm{~s}$, as shown in Figure $4 \mathrm{~A}$. Fluorescence signals of the cell were shown to have increased relative to the background, noted at time points (s) 100, 160, 200, 240, $300,360,440,530$, and 610 , averaging at $578 \pm 108$ counts/s. However, the signals were not high because of the efflux-mediated nature of the $\mathrm{ABC}$ transporters in the absence of an MDR inhibitor.

Subsequently, the cell was treated with $5-\mu \mathrm{M}$ CsA together with $35-\mu \mathrm{M}$ DNR for $\sim 800 \mathrm{~s}$. The results show that, after the cell was treated with DNR in the presence of CsA, an MDR inhibitor, it inhibited the drug efflux process, resulting in MDR reversal, and thus increasing the drug accumulation within the single cell. The fluorescence intensity of the cell began to increase around $890 \mathrm{~s}$ and enhanced dramatically afterwards, averaging at $2109+406$ counts/s. This was caused by the diffusion of DNR into the cell being unaffected 
A

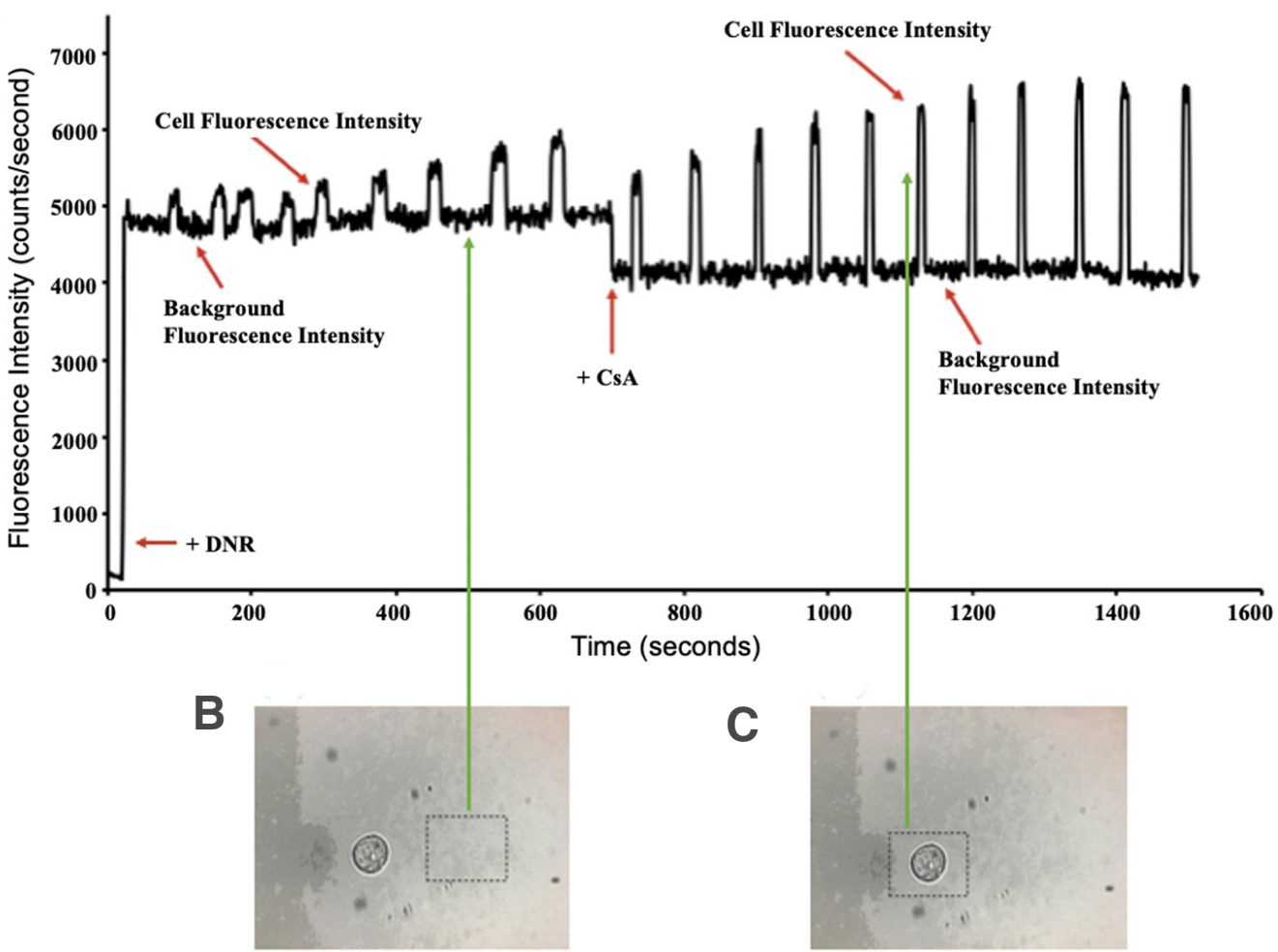

Figure 4. A: The raw experimental fluorescence data are plotted against time with added DNR ( $35 \mu \mathrm{M})$ at $50 \mathrm{~s}$. After $700 \mathrm{~s}, \mathrm{DNR}(35 \mu \mathrm{M})$ $+\mathrm{CsA}(5 \mu \mathrm{M})$ was added. The fluorescence intensity was greatly enhanced, reaching its maximum peak due to non-competitive inhibition of the $A B C$ transporters by $C s A$; $B$ : Fluorescence measurement of detection window (dotted black box) are marked to show the location to measure the background signals; $\mathrm{C}$ : Fluorescence measurement was conducted within the detection window (dotted black box) to monitor the cell signals. DNR: daunorubicin; CsA: cyclosporine A; ABC: ATP binding cassette

regardless of CsA. However, regardless of the uptake of DNR, the ABC transporters were inhibited by CsA. Background-corrected data were obtained by subtracting the background fluorescence from the total fluorescent intensity, and the signal from the cell that represented the dye accumulation in the single cell was given. Background correction from the raw data and fold-increase values were obtained by utilizing the following described formulas:

Equation 1:

$[\text { Fluorescence Intensity }]_{\mathrm{DNR}}=[\text { Fluorescence }]_{\mathrm{CELL}+\mathrm{BACKGROUND}}-[\text { Fluorescence }]_{\mathrm{BACKGROUND}}$

Equation 2:

Fold-Increase of DNR = Fluorescence Signal of Inhibitor Blocked Cell/Fluorescence Signal of Unblocked Cell

Based on the background-corrected data, it was shown that the addition of CsA caused the accumulation of DNR to increase by 3.6 folds, as shown in Figure 5. The experiment of DNR was repeated with both $5-\mu \mathrm{M}$ and $10-\mu \mathrm{M}$ CsA, and the data are listed in Table 1 . The low fold increase was likely caused by the cell being obtained from a higher cell passage, which might suggest a loss in MDR ability.

Figure 6 shows the images of the captured MDA-MB-231 cell before and after the experiment, and after treatment with trypan blue. According to the first image, the cell was round and in a good morphology before the experiment. After treatment with DNR and CsA, the cell's shape changed slightly and appeared 


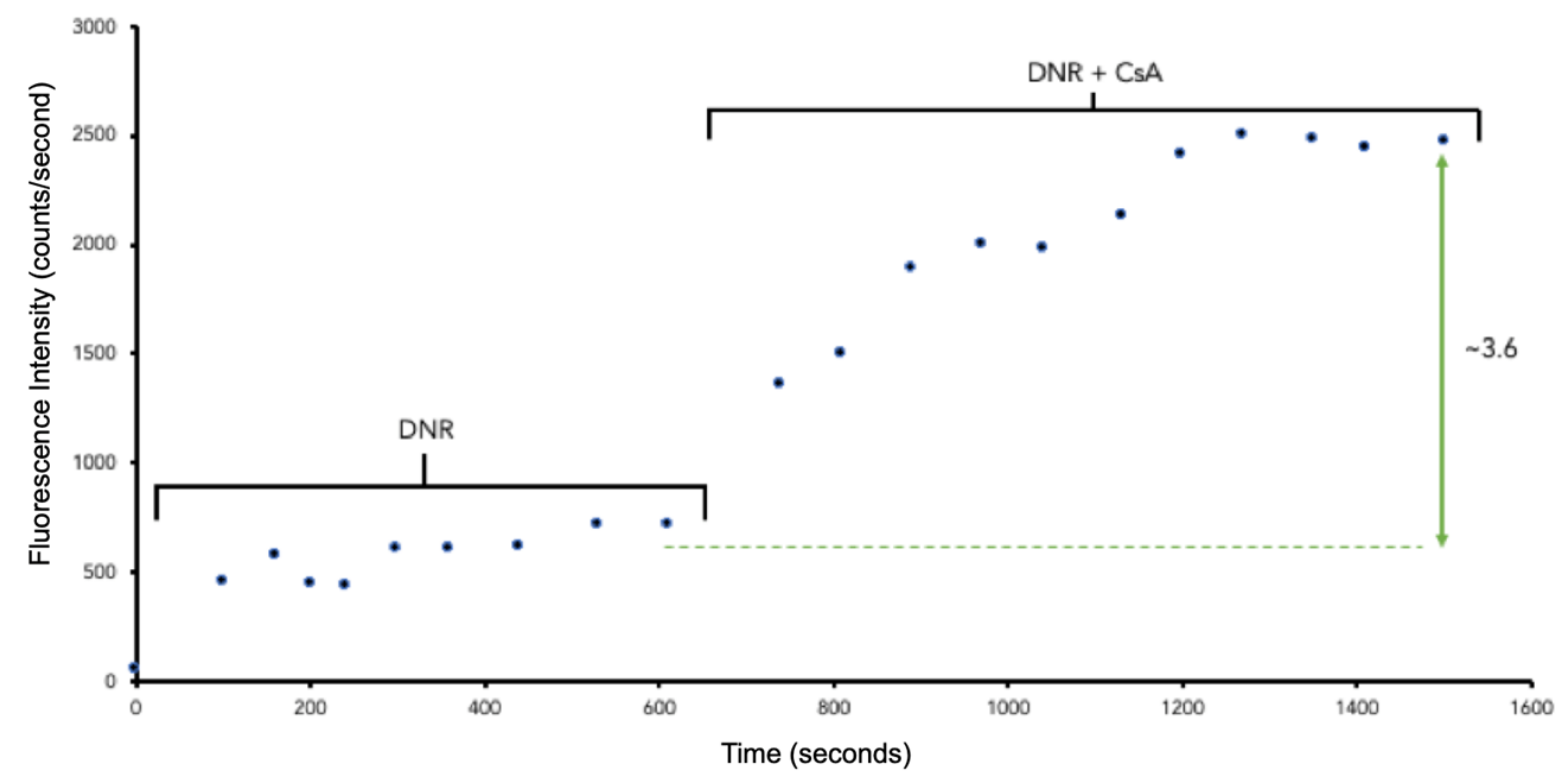

Figure 5. The background corrected experimental fluorescence data (counts/s) due to daunorubicin accumulation in the cell is plotted against time (s). DNR: daunorubicin; CsA: cyclosporine A

Table 1. The average background-corrected fluorescence data (counts/s) for both DNR and OG-PTX (drug only and drug + inhibitor)

\begin{tabular}{llll}
\hline Name of drug & Drug only & Drug $+\mathbf{5} \boldsymbol{\mu M}$ CsA & Drug + 10 $\boldsymbol{\mu M}$ CsA \\
\hline DNR $(35 \mu \mathrm{M})$ & $824 \pm 203$ & $1543 \pm 201$ & $2527 \pm 275$ \\
& $578 \pm 108$ & $2109 \pm 406$ & NA \\
OG-PTX $(1 \mu \mathrm{M})$ & - & $804 \pm 95$ & $2335 \pm 130$ \\
& $836 \pm 269$ & $\mathrm{NA}$ & $2097 \pm 267$ \\
\hline
\end{tabular}

DNR: daunorubicin; CsA: cyclosporine A; OG-PTX: Oregon Green-labeled paclitaxel; NA: not available
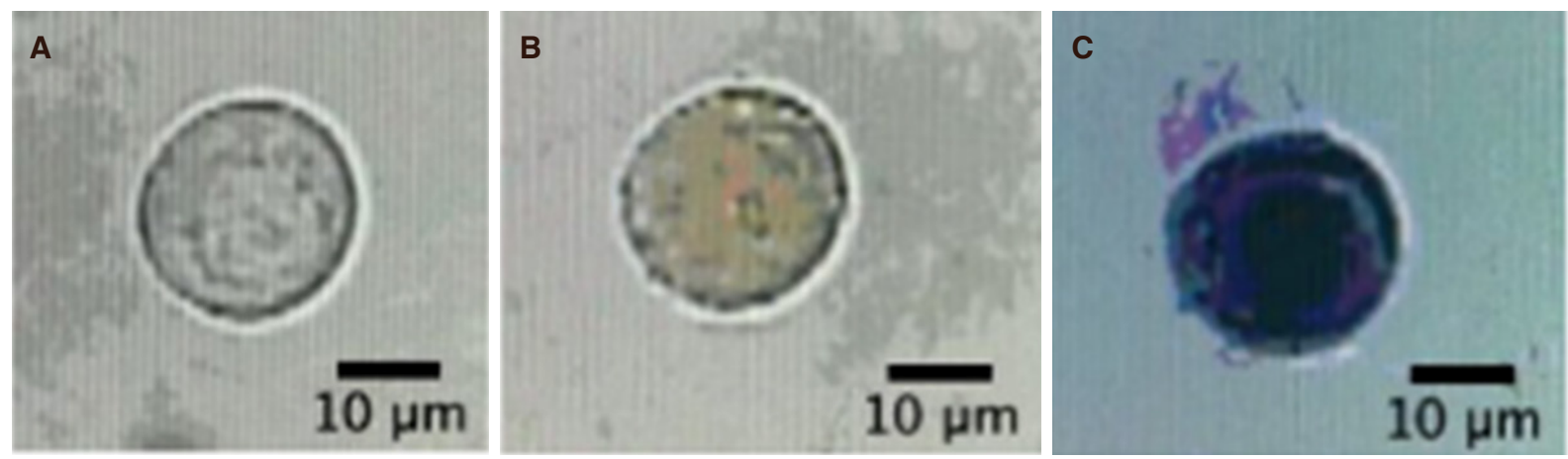

Figure 6. MDR Assay for a single MDA-MB-231 cell. A: Image of the singe cell prior to MDR assay; B: Image of the cell after the MDR assay; C: Image of the cell after the addition of trypan blue, with a 5-min incubation time. MDR: multidrug resistance

orange in regions of the nucleus, indicating the diffusion of DNR into the cell. When trypan blue was used to treat the cell as a final step, it was stained dark blue due to dye penetration through the porous cell membrane into the cytoplasm, thus indicating cell death.

A similar experiment was run using a labeled drug, OG-PTX, and the fluorescent data are shown in Figure 7. As shown in Figure 7A, a breast cancer cell was first treated with $1-\mu \mathrm{M}$ OG-PTX for $\sim 800 \mathrm{~s}$. The results show that, after the cell was treated with the drug in the presence of CsA, it inhibited the drug efflux process, thus 

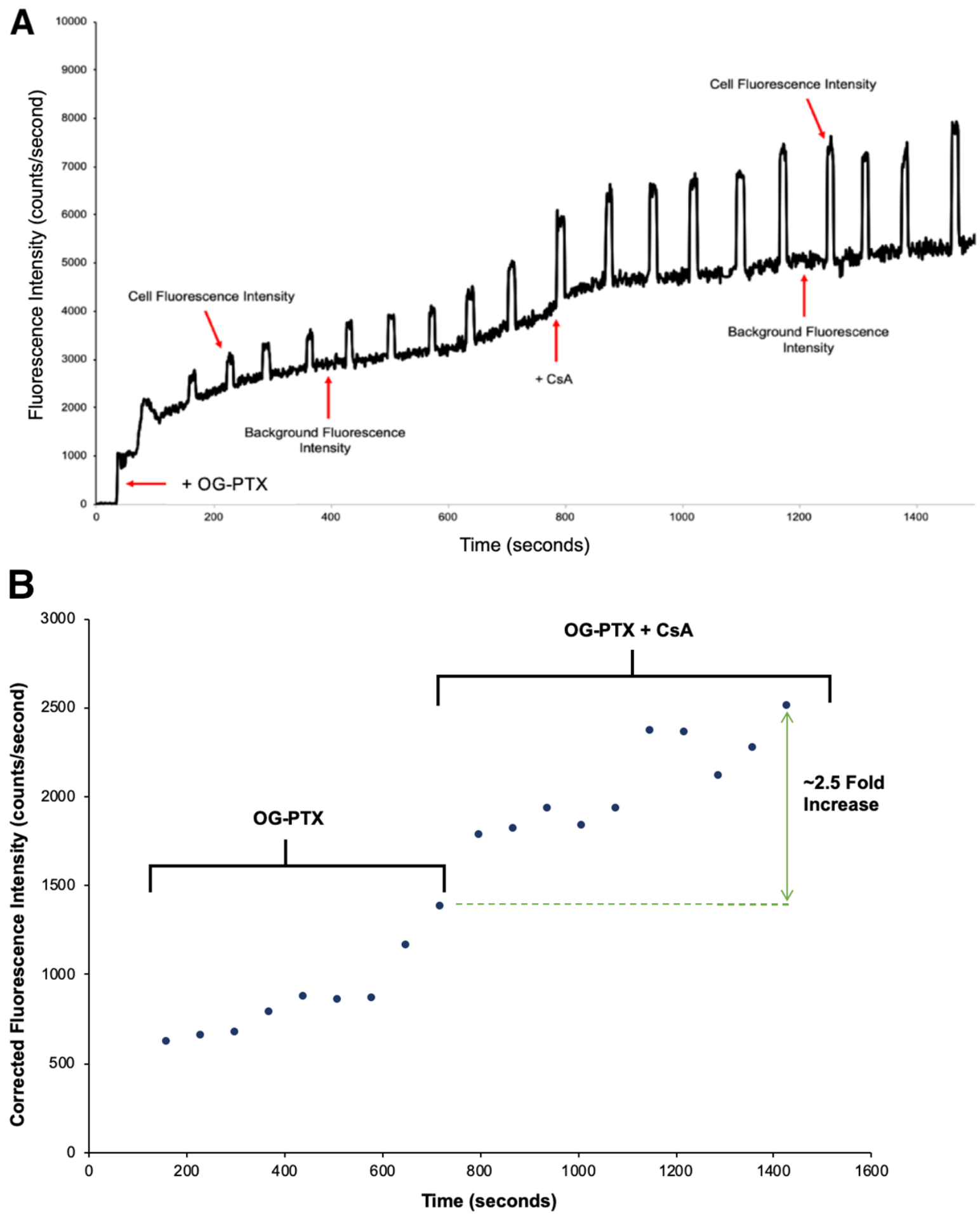

Figure 7. A: The raw experimental fluorescence data are plotted against time with added OG-PTX $(1 \mu \mathrm{M})$ at $50 \mathrm{~s}$. After $800 \mathrm{~s}$, OG-PTX $(1 \mu \mathrm{M})+\mathrm{Cs} A(10 \mu \mathrm{M})$ was added. The fluorescence intensity was enhanced, reaching its maximum value; B: The background corrected experimental fluorescence data (counts/s) due to OG-PTX accumulation in the cell are plotted against time (s). CsA: cyclosporine A; OG-PTX: Oregon Green-labeled paclitaxel

increasing the accumulation of OG-PTX within the single cell. As shown in the background corrected graph in Figure $7 \mathrm{~B}$, the fluorescence intensity of the cell began to increase around $900 \mathrm{~s}$ and enhanced dramatically afterward, averaging at $2097+267$ counts/s, as listed in Table 1. Based on the background-corrected data, 
it was shown that the addition of CsA caused the accumulation of OG-PTX to increase by $\sim 2.5$ folds. The experiment of OG-PTX was repeated, and the data are listed in Table 1. The enhancement of fluorescence intensity of the drug from $5-\mu \mathrm{M}$ to $10-\mu \mathrm{M}$ of CsA was apparent.

\section{DISCUSSION}

This paper reports a microfluidic chip to measure the drug accumulation in single breast cancer cells in order to understand the inhibition of drug efflux properties. Single-cell selection, loading of drugs, and fluorescence measurement for intracellular accumulation of drugs were all conducted on a microfluidic chip. As a result, measurements of the accumulation of chemotherapeutic drugs (e.g., daunorubicin and paclitaxel) in single cells in the presence and absence of CsA were conducted. The results show that drug accumulation in a single-cell greatly enhanced over its same-cell control due to the inhibition by cyclosporine A. This measurement method is limited to one single cell at a time; however, this limitation can be partly resolved by incorporating multiple cell retention structures in the same single cell footprint. This work may provide a platform for future studies to characterize the MDR activity of single cells obtained in liquid biopsy samples.

\section{DECLARATIONS}

\section{Authors' contributions}

Carried out the experiments: Parekh K, Noghabi HS

Analyzed the data: Parekh K, Lopez JA, Li PCH

Data curation and methodology: Parekh K, Noghabi HS, Lopez JA, Li PCH

Funding acquisition: Li PCH, Lopez JA

Project administration, resources and supervision: Li PCH

Writing original draft: Parekh K

Writing review and editing: Parekh K, Noghabi HS, Lopez JA, Li PCH

\section{Availability of data and materials}

The raw data is available upon email request to $\mathrm{PCH} \mathrm{Li}$.

\section{Financial support and sponsorship}

This research as funded by the Discovery Grant Program of Natural Sciences and Engineering Research Council (NSERC) of Canada is gratefully acknowledged. PCHL and HSN thanks the travel support from the Griffith University and Simon Fraser University Collaborative Travel Grant.

\section{Conflicts of interest}

All authors declared that there are no conflicts of interest.

\section{Ethical approval and consent to participate}

Not applicable.

\section{Consent for publication}

Not applicable.

\section{Copyright}

(c) The Author(s) 2020.

\section{REFERENCES}

1. Livasy CA. Pathologic evaluation of triple-negative breast cancer. In: Tan A, editors. Triple-negative breast cancer. Cham: Springer; 2018. pp. 1-22. 
2. O'Shaughnessy JA. Treating breast precancer. Clin Breast Cancer 2000;1:S74-9.

3. Boichuk S, Galembikova A, Sitenkov A, Khusnutdinov R, Dunaev P, et al. Establishment and characterization of a triple negative basal-like breast cancer cell line with multi-drug resistance. Oncol Lett 2017;14:5039-45.

4. Li K, Lai H. TanshinoneIIA enhances the chemosensitivity of breast cancer cells to doxorubicin through down-regulating the expression of MDR-related ABC transporters. Biomed Pharmacother 2017;96:371-7.

5. Germann UA. P-glycoprotein - a mediator of multidrug resistance in tumour cells. Eur J Cancer 1996;32:927-44.

6. Hussein N, Ashby CR, Amawi H, Nyinawabera A, Vij A, et al. Cariprazine, a dopamine D2/D3 receptor partial agonist, modulates ABCG2-mediated multidrug resistance in cancer. Cancers (Basel) 2018;10.

7. Campos L, Guyotat D, Archimbaud E, Calmard-Oriol P, Tsuruo T, et al. Clinical significance of multidrug resistance P-glycoprotein expression on acute nonlymphoblastic leukemia cells at diagnosis. Blood 1992;79:473-6.

8. Xing H, Luo X, Li Y, Fan C, Liu N, et al. Effect of verapamil on the pharmacokinetics of hydroxycamptothecin and its potential mechanism. Pharm Biol 2020;58:152-6.

9. Clarke R, Leonessa F, Trock B. Multidrug resistance/P-glycoprotein and breast cancer: review and meta-analysis. Semin Oncol 2005;32:9-15

10. Coley HM, Twentyman PR, Workman P. The efflux of anthracyclines in multidrug-resistant cell lines. Biochem Pharmacol 1993;46:1317-26.

11. Rabindran S, Ross D, Doyle L, Yang W, Greenberger L. Fumitremorgin C reverses multidrug resistance in cells transfected with the breast cancer resistance protein. Cancer Res 2000;60:47-50.

12. Tatsuta T, Hosono M, Sugawara S, Kariya Y, Ogawa Y, et al. Sialic acid-binding lectin (leczyme) induces caspase-dependent apoptosis-mediated mitochondrial perturbation in Jurkat cells. Int J Oncol 2013;43:1402-12.

13. Wang MM, Tu E, Raymond DE, Yang JM, Zhang H, et al. Microfluidic sorting of mammalian cells by optical force switching. Nat Biotechnol 2004;23:83-7.

14. Gao N, Li X. Controlled drug delivery using microfluidic devices. In: Li X, Zhou Y, editors. Microfluidic devices for biomedical applications. Woodhead Publishing Limited; 2013. pp. 167-84.

15. Benhabib M, Li X. Low-cost assays in paper-based microfluidic biomedical devices. In: Li X, Zhou Y, editors. Microfluidic devices for biomedical applications. Woodhead Publishing Limited; 2013. pp. 492-526.

16. Dou M, García JM Jr, Zhan S, Li X. Interfacial nano-biosensing in microfluidic droplets for high-sensitivity detection of low-solubility molecules. Chem Commun (Camb) 2016;52:3470-3.

17. Dou M, Macias N, Shen F, Bard JD, Domínguez DC, et al. Rapid and accurate diagnosis of the respiratory disease pertussis on a point-of-care biochip. EClinical Medicine 2019;8:72-7.

18. Harrison DJ, Fluri K, Seiler K, Fan Z, Effenhauser CS, et al. Micromachining a miniaturized capillary electrophoresis-based chemical analysis system on a chip. Science 1993;261:895-7.

19. Li XJ, Li PCH. Cytosolic calcium measurement for single-cell drug efficacy and cardiotoxicity evaluations using microfluidic biochips. Can J Pure Appl Sci 2014;8:2663-9.

20. Jin W, Li X, Gao N. Simultaneous determination of tryptophan and glutathione in individual rat hepatocytes by capillary zone electrophoresis with electrochemical detection at a carbon fiber bundle - Au/Hg dual electrode. Anal Chem 2003;75:3859-64.

21. Shen F, Li X, Li PCH. Study of flow behaviors on single-cell manipulation and shear stress reduction in microfluidic chips using CFD simulations. Biomicrofluidics 2014;8:014109.

22. Yildiz HB, Freeman R, Gill R, Willner I. Electrochemical, photoelectrochemical, and piezoelectric analysis of tyrosinase activity by functionalized nanoparticles. Anal Chem 2008;80:2811-6.

23. Zhao XP, Zhou Y, Zhang QW, Yang DR, Wang C, et al. Nanochannel-ion channel hybrid device for ultrasensitive monitoring of biomolecular recognition events. Anal Chem 2018;91:1185-93.

24. Khamenehfar A, Beischlag TV, Russell PJ, Ling MTP, Nelson C, et al. Label-free isolation of a prostate cancer cell among blood cells and the single- cell measurement of drug accumulation using an integrated microfluidic chip. Biomicrofluidics 2015;9:064104.

25. Li X, Li PCH. Microfluidic selection and retention of a single cardiac muscle cell, on-chip dye loading, cell contraction by chemical stimulation and quantitative fluorescent analysis of intracellular calcium. Anal Chem 2005;77:4315-22.

26. Li X, Huang J, Tibbits GF, Li PCH. Real-time monitoring of intracellular calcium of a single cardiomyocyte in a microfluidic chip pertaining to drug discovery. Electrophoresis 2007;28:4723-33.

27. Khamenehfar A, Wan CPL, Li PCH, Letchford K, Burt HM. Same-single-cell analysis using the microfluidic biochip to reveal drug accumulation enhancement by an amphiphilic diblock copolymer drug formulation. Anal Bioanal Chem 2014;406:7071-83.

28. Khamenehfar A, Li PCH, Leung ELH. Gefitinib enhanced cancer drug uptake in the same single non-small cell lung cancer cells observed in real-time in the microfluidic biochip. Can J Pure Appl Sci 2018;12:4375-80.

29. Li XJ, Xue X, Li PCH. Real-time detection of the early event of cytotoxicity of herbal ingredients on single leukemia cells studied in a microfluidic biochip. Integr Biol (Camb) 2009;1:90-8.

30. Khamenehfar A, Gandhi MK, Chen Y, Hogge DE, Li PCH. Dielectrophoretic microfluidic chip enables single-cell measurements for multidrug resistance in heterogeneous acute myeloid leukemia patient samples. Anal Chem 2016;88:5680-8.

31. Li X, Chen Y, Li PCH. A simple and fast microfluidic approach of same-single-cell analysis (SASCA) for the study of multidrug resistance modulation in cancer cells. Lab Chip 2011;11:1378-84.

32. Chan LLY, Rice WL, Qiu J. Observation and quantification of the morphological effect of trypan blue rupturing dead or dying cells. PloS One 2020;15;e0227950. 